\title{
El Juli jesuítico ¿Modelo misional o Proyección historiográfica?
}

The jesuit Juli. Model mission or historiographical Projection?

Ricardo González*

\section{Resumen}

El artículo propone una visión divergente de la establecida en relación con el carácter de la acción de los jesuitas en Juli, considerando algunos conflictos que evidencian la tensión relativa a disputas por tierras con los forasteros y su empleo como mano de obra de los religiosos, así como la existencia de manejos arbitrarios por parte de padres y caciques, esto es, algo similar a lo que ocurría en los otros pueblos de indios, contra la visión complaciente de la historiografía tradicional. Finalmente se contradice la idea difundida de haber sido Juli el modelo de las misiones del Paraguay, planteando una perspectiva contraria: en Paraguay los jesuitas trataron de evitar los elementos que dificultaron el desarrollo positivo de la reducción del Titicaca.

\section{Palabras clave}

Juli - jesuitas - reducciones - conflictos

\section{Abstract}

The article proposes a divergent view from the established vision on the character of the action of the Jesuits in July considering some conflicts that show the stress on land disputes with outsiders and their use as labor by the religious, as well as the existence of arbitrary management by friers and curacas. That is, something similar to what happened in other Indian towns, against the complacent view of traditional historiography. Finally, we contradict the disseminated idea of considering Juli the

\footnotetext{
* Profesor Titular de Arte Americano I (colonial) en la Fac. de F y L / UBA y Director de la Maestría en Patrimonio artístico y cultura en Sudamérica colonial.
}

85 Ricardo González. El Juli jesuítico.¿Modelo misional o Proyección historiográfica...: 85-100 
model of the Paraguay missions, proposing a contrary view: in Paraguay the Jesuits attempted to avoid the elements that hindered the positive development of the Titicaca reduction.

Key Words: Juli, Jesuit reductions, conflicts

Recibido: 19 de junio de 2014

Evaluado: 30 de junio de 2014 
En noviembre de 1576 y como resultado de un proceso de debate acerca de la conveniencia de hacerse cargo de misiones entre los pobladores americanos ${ }^{1}$ que había comenzado antes de la llegada del virrey Toledo a Perú y había resultado en la aceptación de las doctrinas de Huarochirí, abandonada por los dominicos, y el Cercado de Lima ${ }^{2}$, los padres de la Compañía de Jesús llegaron al pueblo de Juli en la "laguna de Chucuito" con el objeto de hacerse cargo del adoctrinamiento de los lupacas que lo habitaban. Se abre así el capítulo más interesante de las numerosas experiencias reduccionales impulsadas por la Corona española en América con el doble fin de evangelizar a los indígenas y de iniciar un proceso de transculturación capaz de integrarlos a las necesidades productivas de los conquistadores. La indudable significación que reviste este emprendimiento reduccional de carácter permanente por parte de la orden en América española ha sido resaltada reiteradamente por los historiadores que desde diversas perspectivas abordaron el tema en enfoques dirigidos a describir y explicar el proceso de Juli en sus aspectos institucionales, religiosos, arquitectónicos o artísticos. Pese a la diversidad de intereses y perspectivas, la mayor parte de los autores coinciden sin embargo en cierta homogeneidad valorativa con que esta experiencia jesuítica es presentada y con la tajante distinción entre el proceso de Juli y la contemporánea evolución de los otros seis pueblos de la provincia de Chucuito. La "Roma andina" o "el pueblo santo", como lo llamaban los mismos jesuitas, emerge en esas miradas como un oasis de justicia y equidad en medio del desolador panorama de abusos impuestos a las comunidades indígenas de Chucuito, Ácora, Ilave, Pomata, Zepita y Yunguyo por curas, funcionarios y caciques y del aún más siniestro destino de la mita de Potosí, que caracterizaba la vida de toda la provincia, pero que en Juli parece adoptar un cariz menos cruel en virtud de la implantación de mecanismos sociales compensatorios que, si no impedían el hecho, mitigaban su alcances nocivos.

El capítulo dedicado a Juli en Los jesuitas del Perú (1941), del padre Rubén Vargas Ugarte S.J., es indudablemente un buen ejemplo de esta afirmación. Vargas reproduce en su texto descripciones provenientes de documentación producida por los mismos padres o encomiosos comentarios de funcionarios de la Corona, como la carta que el Marqués de Mancera enviara al Rey en 1642: "Por las noticias que tengo de estas doctrinas y las que he procurado especiales... puedo afirmar a VM que en la Relación que hace el P. Provincial... anduvo corto... porque el arte con que lo gobiernan, el inmenso trabajo que les cuesta, la puntualidad con que doctrinan a los indios, la piedad con que los curan y el valor con que los defienden de las molestias que suelen hacerles los españoles, es todo digno de grande admiración y que se atribuya a obra más que humana” 3 .

La visión ponderativa de Vargas Ugarte fue reiterada por gran parte de quienes trataron el tema posteriormente, al punto que el capítulo que dedica Norman

\footnotetext{
${ }^{1}$ La recopilación de documentos y cartas anuas jesuíticas del Perú de Antonio de Egaña permite (volumen 2 (passim), seguir las alternativas de la discusión relativa a la conveniencia o no de tomar misiones o doctrinas entre los naturales que implicasen el ejercicio de la cura de almas.

2 Egaña, 1954, v. 2: 375. Ver también, Page, 2012: 30-32.

${ }^{3}$ Vargas Ugarte, 1941: 37.

87 Ricardo González. El Juli jesuítico.¿Modelo misional o Proyección historiográfica.... 85-100
} 
Meiklejohn a Juli lleva por título "Los jesuitas en Juli: doctrineros modelo” y Ramón Gutiérrez denomina "Juli o la utopía de la comunidad cristiana bajo un régimen colonial” al acápite en que da cuenta de las ventajas del régimen jesuítico en el Collao. ${ }^{4}$ Huelga decir, porque lo expresan sus títulos, que ambos autores asignan al régimen establecido por la Compañía en Juli un carácter superlativo, guiado exclusivamente por el afán de promover la salvación y el bienestar de los indios, es decir, consideran efectiva la construcción de una pragmática idéntica a los fines ideales y los discursos que materializaba. Se trataba, en palabras de Gutiérrez, de "jerarquizar una nueva escala de valores donde desaparecía como objetivo la acumulación de riquezas por los religiosos”, 5 y esta nueva escala de valores se expresaba no sólo en el cumplimiento eficiente de la tarea pastoral sino también en la "benevolencia de los jesuitas con respecto a los que se encontraban a su cargo" que se manifestaba en forma de limosnas a los pobres, atención hospitalaria, educación, contribuciones para el pago del tributo y sostén a los mitayos. Afirma Mieklejohn: “... No pretendían hacer trabajar a los indígenas para ellos como recaderos. ... No los golpeaban ni los llamaban con nombres infamantes. Si juzgaban que un indígena merecía castigo, hacían que lo impartiesen los funcionarios civiles designados por la ley para este fin”, afirmación consignada igualmente por Vargas Ugarte: “existía cárcel, pero las penas eran muy moderadas: el encierro o unos cuantos azotes, castigo muy en uso entre los indios, y que sólo aplicaban los ministros de justicia, nunca los curas". 6

Pese a que esta complaciente mirada es puesta en tela de juicio por las evidencias que ciertos documentos proporcionan o por descripciones menos teñidas por el fervor propio de la misma empresa que algunos visitadores elaboraron, sus denuncias no parecen merecer un análisis detenido en la historiografía tradicional o son puestas entre paréntesis a la hora de situarlos en un contexto de consideración general. Más comúnmente se vinculan los problemas a razones externas al accionar de la orden, inmersa en una situación que en muchos aspectos no podía revertir, lo que no deja de expresar una parte de los problemas. Alfonso de Echánove, por ejemplo, comienza su artículo sobre la evolución de la idea de reducción en el mundo jesuítico aludiendo a las "infinitas dificultades, incertidumbres, retrocesos y problemas canónicos” de la experiencia misional ignaciana ${ }^{7}$ y Ramón Gutiérrez, en su remarcable estudio de la arquitectura del altiplano peruano, señala "el sistema socio-económico al cual están sujetos los indígenas” de Chucuito, como la causa fundamental de las dificultades arrostradas. ${ }^{8}$

Sin embargo, los mismos jesuitas inmersos en el proceso tuvieron a veces juicios críticos sobre la marcha del adoctrinamiento. La descripción descarnada de los primeros años dada por el visitador Juan de la Plaza, que residió en Juli y no comparte el entusiasmo general, muestra un panorama bien distinto al de las crónicas

\footnotetext{
${ }^{4}$ Meiklejohn, 1988: 191 y Gutiérrez, 1986: 357.

${ }^{5}$ Gutiérrez, 1986: 359.

${ }^{6}$ Meiklejohn, 1988: 216 y Vargas Ugarte, 1941: 45.

${ }^{7}$ Echánove, 1955: 95.

${ }^{8}$ Gutiérrez, 1986: 325.
} 
ordinarias. Plaza alude a su experiencia directa en la doctrina al señalar que "el fruto no es tanto como suena, ni las dificultades tan pocas y fáciles” y afirma con cierto desencanto que "a la doctrina vienen pocos por su voluntad". Muchos se escondían para no asistir a las pláticas y a los sermones, mientras que los domingos a la mañana hacía falta "poner alguaciles en la calles para que [los indios] no se vayan a trabajar al campo". 9 La persistencia de los cultos locales es otro signo de las dificultades de la evangelización. La Carta Anua de 1600 consigna que "se habían descubierto muchos indios e indias hechiceros" los que habían sido alojados en una casa especial, "la casa blanca”, "diputada para recoger y remediar esta gente”. En eso el panorama en Juli se pinta de todos modos más controlado que en el resto de la provincia, donde "muchos de ellos [los indios] guardan sus ritos y ceremonias como el primer día, adorando sus huacas, ofreciéndoles sacrificios, reverenciando las piedras y los montes con muchos géneros de supersticiones y diabólicas ceremonias”. ${ }^{10}$

Estas objeciones o explícitos problemas no opacan sin embargo la consideración general del proceso, reforzada por el argumento demográfico. La mayor parte de los autores coincide en un proceso poblacional expansivo, a contramano de la tendencia a la despoblación de las comunidades en el resto de la provincia. Este es quizás un argumento más sólido que los juicios derivados de la correspondencia jesuítica ya que no media la subjetividad ni el interés del cronista y, tal como ocurre hoy día, es cierto que la gente suele irse de los sitios ingratos hacia lugares más acogedores. Según Vargas Ugarte "había al arrancar los jesuitas 3.200 indios de tasa, 16.000 almas en total y según el mismo autor, en 1620 se debieron edificar "50 nuevas casas para dar albergue a los que de otras partes se habían acogido a Juli" "11. Parece efctivamente, haber habido incentivos para la localización de indios ajenos a la doctrina. Meiklejohn sostiene por ejemplo, que la generosidad de los padres de la Compañía no se limitaba a los habitantes de Juli, sino que "tanto los jesuitas como los del pueblo atendían y daban limosnas a la gente necesitada que habitaba los alrededores. Tan atractiva encontraban la ayuda estos foráneos, que muchos de entre ellos decidían establecerse en Juli. Otros beneficiarios eran sencillamente indígenas transeúntes que carecían de abrigo y comida y encontraban ambas cosas a su paso por Juli" ${ }^{\text {"12 }}$. La carta anua de 1602 señala que en virtud de estas limosnas, "sabiendo los indios el refrigerio que tienen aquí en todos sus trabajos, se viene a este pueblo mucha gente de los demás, especialmente la que es moza, que por tener seguridad y servir a Nuestro Señor se acogen a este puesto". ${ }^{13}$ Esta generosa asistencia a los foráneos llevó a su rápida multiplicación: en las cartas anuas de 1627-1628 consignan que 6.000 forasteros habían sido confesados en Juli y 2.600 lo fueron en la Navidad de $1639,{ }^{14}$ cifras y hechos que muestran tanto una gran afluencia de indios de otros pueblos como la mejor disposición a recibirlos y

\footnotetext{
${ }^{9}$ Echánove, 1955: 133.

${ }^{10}$ Egaña y Fernández, 1981: 104 y Fernández, 1986: 313 y 308.

${ }^{11}$ Vargas Ugarte, 1941: 39 y 46.

${ }^{12}$ Meiklejohn, 1988: 215.

${ }^{13}$ Fernández, 1986: 307, Egaña y Fernández, 1981: 107.

${ }^{14}$ Meiklejohn, 1988: 238.
}

89 Ricardo González. El Juli jesuítico.¿Modelo misional o Proyección historiográfica...: 85-100 
favorecer su establecimiento.

La bibliografía clásica sobre el emprendimiento jesuítico nos muestra así un campo experimental en el que el concepto mismo de misión es creado, desarrollado y puesto a prueba y en el que tanto la superioridad intelectual de la orden ignaciana como el establecimiento de ciertas pautas éticas, metodológicas y organizativas, contrastaban con las formas poco sistemáticas -y en el caso particular del Collao poco éticas- de las experiencias precedentes y contemporáneas. Las reducciones dominicas, criticadas por los indios, por la visita de Garci Diez de San Miguel y por el mismo virrey Toledo habían sido un modo de usufructo del trabajo indígena antes que un programa evangelizador. Gutiérrez señala que como resultado del reordenamiento impuesto por el virrey, Juli desplazará del liderazgo zonal a Chucuito en virtud del "sistema de organización y catequesis de los jesuitas, que prestigiado ante los indígenas originará un proceso de migración interna y posibilitará el crecimiento de Juli”. ${ }^{15}$

De este modo, contra la visión negativa de las experiencias anteriores, la aparición jesuítica en 1576 se presenta como la implantación de un sistema justo, ordenado y racional en el que, desde el estudio de la lengua hasta la creación de una rutina doctrinal, laboral y vital -sugerencias que el provincial José de Acosta, mentor del establecimiento a instancias de Toledo, incluirá en su De procuranda indorum salute- moldean la imagen de una aceitada organización en la que la experiencia posterior del Guayrá parece asomar in nuce. Por una cuestión cronológica y conceptual ese fue naturalmente el criterio, ya señalado por Vargas Ugarte y repetido por los autores que siguieron: "el hecho de haber sido la doctrina de Juli en el Perú la que sirvió de modelo a las demás reducciones de indios y la escuela donde se formaron los primeros misioneros y donde se elaboró, por así decirlo, el sistema que más adelante con ligeras variantes había de seguirse en todas ellas”. ${ }^{16}$

Para este conjunto de autores la experiencia de Juli se distingue claramente de lo sucedido en el resto de la provincia y constituye una especie de oasis donde acudían indios huidos de otros pueblos a refugiarse de la injusticia. Esta pintura claroscurista y casi maniquea, en un ámbito geográfico, institucional, económico y cultural relativamente uniforme, de extensión módica y bien delimitado, como es la provincia de Chucuito, debería resultar sorprendente.

En parte esto tiene una explicación evidente: el factor común de las miradas ponderativas son las fuentes en que se apoyan. La actividad de los jesuitas en Juli está bien documentada, sobre todo para las primeras décadas, ${ }^{17}$ pero en gran parte esta documentación fue producida por los mismos jesuitas o por funcionarios afines a ellos, por lo que el carácter benévolo de su mirada resulta casi necesario. ¡Qué diferente sería la historia de los dominicos en el Collao si se tomasen como

\footnotetext{
${ }^{15}$ Gutiérrez, 1986: 279.

${ }^{16}$ Vargas Ugarte, 1941: 37.

${ }^{17}$ Las cartas y documentos relativos a estas décadas fueron publicadas por Antonio de Egaña y Enrique Fernández en Monumenta Peruana (8 volúmenes) que integran la "Monumenta Historica Societatis Jesu”, Roma, 1954-1986.
}

90 Ricardo González. El Juli jesuítico.¿Modelo misional o Proyección historiográfica...: 85-100 
referencia las afirmaciones del provincial de la Cerda, que ve sólo émulos de la entrega de los predicadores a la defensa de los indios en los críticos de su orden! ${ }^{18}$ En segundo lugar, varios de los historiadores que compusieron el relato de Juli han obrado con un criterio selectivo que puede ponerse en duda. Si la laudatoria puede ser sincera y seguramente basada en factores verdaderos, aunque muchas veces magnificados, difícilmente los historiadores jesuitas o "projesuitas", con excepción de Meiklejohn, se muestran dispuestos a incorporar en sus trabajos afirmaciones divergentes de esta perspectiva, que indudablemente las hubo, y que matizarían la pintura. El fin de este trabajo es justamente poner a la vista algunos documentos que "divergen" de la historia oficial, no con el fin de negarla, sino de mostrar que, como sensatamente debería suponerse, la "Roma andina" formaba también parte de una realidad general más compleja, que el panegírico con que comúnmente se hace referencia a ella, no explica.

Como lo testimonia la visita de Plaza, los problemas existieron desde las primeras décadas y por momentos tomaron un cariz crítico. El primer documento que querría considerar fue presentado al gobernador de Chucuito por las autoridades indígenas de Juli el 10.2.1679: "Pablo Airo, Don Carlos Velasco, Don Lorenzo Quenaya, don Juan Pongopina, principales caciques del pueblo de Juli, en voz y nombre de los demás mandones" presentaron ante las autoridades de Chucuito una queja denunciando "la tiranía de los padres de Juli”. Según el testimonio, los padres pedían 40 indios a las cuatro parcialidades "para guarda de sus ganados que son infinitos en las punas”. Acabado el año los indios solían terminar en la cárcel por no poder responder por "los que se le perdieron y murieron". Por esta razón no querían prestar el servicio "y lo pagamos los caciques con malos tratamientos que nos hacen [los padres] hasta llegar a azotarnos ya en la cárcel, ya en sus celdas, culpándonos de la omisión de los indios". Los jesuitas les pagaban 30 pesos pero descontados los faltantes "no solamente no les queda nada pero quedan empeñados por muchos años, para que prosigan en la guarda de los carneros".

El segundo punto de la queja tocaba a la presencia de forasteros:

Las tierras que ocupan los padres con sus ganados son mucha, con las chacras que hacen ocupan muchísima, los indios forasteros son, como a V. Md. le consta, muchos, que los van agregando los padres y para estos y sus chacras no ha de faltar tierras, pero para los pobres tributarios todo falta porque no son para los padres de tanto útil como los otros y parece que tiran a que no quede indio tributario según vuelven por los forasteros que ya no caben en toda la jurisdicción chacras para ellos y al contrario los pobres tributarios sólo son para que vayan a los viajes que hacen los padres.

Detallan los diversos servicios que cubrían: a Arequipa por vino, a

${ }^{18}$ Meiklejohn, 1988: 55.

91 Ricardo González. El Juli jesuítico.¿Modelo misional o Proyección historiográfica...: 85-100 
Cochabamba por harinas, a los valles por maíz, con arreos de carneros a vender a Potosí. El argumento sigue con la imposibilidad de "acudir a las tasas y mita de Potosí" que esta situación acarreaba (puntos que sensibilizaban a los funcionarios de la Corona), lo que según los caciques no preocupaba a los jesuitas ya que esperaban que "los 5000 ps. que tienen designados se les den de las Cajas reales de esta ciudad" y aún van más lejos al afirmar que en realidad los padres buscaban "que se quite totalmente la tasa y no haya ocasión de que entre al pueblo la Justicia porque los padres prenden, sueltan, trasquilan, azotan y son los tenientes”. Los caciques amenazan con llevar adelante su protesta si no los escuchan, asegurando que "ellos [los jesuitas] como poderosos consiguen todo lo que quieren y si V. Md. no nos ampra nos iremos del pueblo a la Real Audiencia a pedir justicia”.

Finalmente acusan a los padres de las malversaciones corrientes en todas las doctrinas de indios: abuso en los aranceles (habían cobrado por el entierro del padre de uno de los reclamantes 471 pesos), retención de herencias y también venta de las casas de los tributarios a los forasteros, afirmando que "ya no tenemos los pobres caciques e indios tributarios ni tierras para los ganados ni para chacras, todo lo ocupan los forasteros que son muchos". Piden a las autoridades "tierras bastantes” y que "mande a los caciques de la provincia vayan por sus indios a sacarlos de Juli" pues en dho. pueblo no sirven de nada a su Magd. y "que los Padres no nos maltraten". Por fin, que "la pulpería del pueblo la den a los caciques por sus turnos y no a los forasteros como la han dado.” El gobernador dictamina que los caciques recurran a los tribunales superiores. ${ }^{19}$

El documento citado muestra una realidad muy diferente a la magnanimidad y el orden que traslucen las primeras crónicas y pone sobre el tapete algunas cuestiones estructurales. Las relativas al maltrato y abuso laboral y económico de los indios pertenecen a las modalidades usuales en las doctrinas de indios y pueden rastrearse también en las recomendaciones de los provinciales jesuitas. En 1722 el provincial Antonio Garrido, reiterando órdenes dadas por el visitador Diego Altamirano a fines del siglo XVII -casi dos décadas después de la denuncia de los caciques- señaló que "los jesuitas de Juli, tal como hacían los jesuitas peruanos, se han aprovechado del trabajo de los nativos, utilizándolo en su propio provecho y disponiendo de él a favor de otros". También los acusa de abandonar la defensa de los indígenas. La conclusión de Norman Meiklejohn, como vimos abierto defensor de la labor de la Compañía, es simple y sincera: los jesuitas "se habían vuelto explotadores como todos los demás”. El provincial recomendaba igualmente que no se permitiese la habitación en el pueblo de mestizos, mulatos e indios vagabundos, aludiendo indudablemente a los "forasteros" que vimos aparecer con un papel muy significativo en la carta presentada por los caciques al gobierno en $1679 .{ }^{20}$ Los mandatos de visitadores y provinciales no sólo acreditan lo expuesto por los caciques sino que le dan escala temporal. La protesta fue elevada en 1679, las instrucciones de Altamirano rondan 1700 y las reconvenciones de Garrido son de 1722. Los abusos habían durado más de 40 años y los forasteros aparecen a lo largo de este período

\footnotetext{
${ }^{19}$ ANB, Cartas Real Audiencia nro. 1334 (1679).

${ }^{20}$ Meiklejohn, 1988: 219.
}

92 Ricardo González. El Juli jesuítico.¿Modelo misional o Proyección historiográfica...: 85-100 
integrados como parte sustancial del sistema y origen de algunos de sus problemas.

Otro documento del Archivo Nacional de Bolivia, de 1762, agrega información al papel de los forasteros. Ese año, el procurador de los jesuitas Diego de Paz pidió indios para cuidar las 9.000 ovejas que el colegio de Arequipa tenía en el Collao. El Virrey Conde de Villar se los concedió (5.10.1762) de los pueblos de Mañaso, Nilque y Hatuncolla. La cuestión estaba ligada a la pérdida de la exención del tributo y mita a los yanaconas, lo que obstruía su servicio a los padres, y venía de fines del siglo XVII. Justamente, el documento de 1762 incorpora como antecedente lo obrado por el padre Felipe de Albizuri, entonces rector de la casa del pueblo de Juli y cura de la Asunción, quien el 14.05.1695 afirma que "desde tiempo inmemorial (1589) a esta parte y aún desde que se fundó aquella casa están agregados algunos indios yanaconas de los que llaman vagos y forasteros que no conocen domicilio, cacique, ni reducción, ni pueblo." Queda claro que los términos "yanaconas" y "vagos y forasteros" designan un mismo sujeto social.

Los yanaconas servían a los padres y en la casa con el cargo de pagarles su trabajo personal, sin embargo de haberles comprado la Compañía cantidad de tierras (estancia Suvicani) "donde están recogidos y hacen sus sementeras ... a los cuales dichos yanaconas jamás se les ha cobrado por los cuatro caciques de dicho Pueblo, ni de otras provincias, tasa ni obligación de ninguna mita, atento a estar destinados al servicio de dha. casa y asistencia de los padres della". ${ }^{21}$

Según el rector "con la variedad [cambio] que ha habido... por pretender obligarles a ellas [tributo y mita], se han ausentado [los yanaconas] con sus familias e hijos, quedando los dichos Padres Curas y Casa, sin el servicio que necesitan". Albizuri afirma que, contrariamente a los demás curas de la provincia, los jesuitas "no pueden valerse de los originarios por estar de ordinario repartidos en servicio de las mitas los más del dicho Pueblo y los otros descansando de los que vienen del servicio" y pide le manden indios de labor sin otras obligaciones, solicitud denegada por el fiscal. ${ }^{22}$ El Teniente de Capitán General y Justicia Mayor de la provincia don Valenzuela y Peralta ordenó entonces recoger testimonios para conocer el verdadero estado de cosas, presentándose como testigos los caciques de las cuatro parcialidades de Juli: ayancas, mochos, chabillas (chimbayas) y guancollos. El alcalde mayor del cabildo indígena, indio "ladino pero con traductor" declaró entonces que: "desde que tiene uso de razón sabe y ha visto que los Padres de este Colegio han agregado a los pobres indios huérfanos y forasteros que suelen venir de Provincias distintas de esta y darles así el sustento necesario como tierras para sus sementeras, y que por el buen tratamiento y estar bien instruidos en el misterio de nuestra santa fe católica se han agregado dichos indios”.

Según el testimonio del alcalde mayor indígena "había muy cerca de 150" de los cuales en ese momento "apenas habrá 50". Como lo señalan algunos de los caciques -y explica el cambio de actitud de los indios originarios respecto de los forasteros- la obligación de tributar para los yanaconas perjudicaba no solo a los

\footnotetext{
${ }^{21}$ ANB, 1762, 62.

${ }^{22}$ ANB, 1762, 62 v-63.
} 
padres sino también a las parcialidades, ya que requería recursos que se descontaban de su ayuda al tributo indígena. El informe del teniente Valenzuela y Peralta del 26.10.95 consigna que "el colegio de esta casa ... les daba de limosna a los cuatro caciques de este pueblo en los años pasados 2.200 ps., y al presente les da en cada uno 1.100 ps. para ayuda del entero de sus tributos librándolos en sus sínodos” ${ }^{23}$. La inspección incluye un padrón de los yanaconas adscriptos a las parcialidades en el que se manifiesta que todos los censados son originarios de otros pueblos, aunque en una especie de repentina amnesia colectiva casi todos dicen desconocer su propio lugar o etnia de origen. Finalmente, el virrey Melchor Portocarrero Laso de la Vega, determina que "por no poder valerse de los originarios [para el servicio] "se les despache provisión amparando a dichos Padres en la posesión en que habían estado de dichos yanaconas", términos que se reproducen en el decreto del 6.2.1696 donde explicita que quedaban los padres en "posesión de la mita que tuvieran de los indios forasteros que asisten en la Estancia de Suvicani". ${ }^{24}$ Sin embargo, como vimos, en 1762 el problema de los forasteros-yanaconas había resurgido.

El tercer documento del archivo de Sucre es una queja de los caciques dirigida al Teniente General Diego Martínez Hendo, denunciando el maltrato a que los sometía el también cacique, aunque por el tenor de las afirmaciones de rango superior, José Alejandro Sapana. Carlos de Velazco cacique principal y gobernador de la parcialidad de los mochos, así como el resto de los caciques del pueblo, señalan que Sapana -que en realidad era un intruso "nieto de un indio yanacona de los pacajes llamado Andres Cusi y reducido al ayllo de los incas," es decir la parcialidad que tenía por parroquia Santa Cruz- ${ }^{25}$ había provocado que su parcialidad fuera "en mucha disminución por los agravios y malos tratamientos” cometidos.

Los indios de tasa habían disminuido de 476 a 200 al pasar el gobierno general de Velazco a Sapana, quien es acusado de enriquecimiento ilícito por medio de la enumeración de sus numerosas estancias y ganado, señalando que "cuando entró al gobierno no tuvo tales bienes”. Los había obtenido haciendo trabajar a los indios para sí, tomando sus tierras para pastura, nombrando "cada año 7 o 8 indios colque haqui y cobra a cada uno a 150 pesos y a $130 \ldots$ con pretexto de la mita”. ${ }^{26}$ Sapana, quien según Martínez Hendo actuaba en connivencia con el justicia mayor Bartolomé de Valenzuala y Peralta, había llegado al extremo de cobrar un peso por indio por sus servicio de gobierno. El reclamo estaba firmado por las parcialidades: Mocho, Yauricopa, Asarape, Chacolle, Sulli, Ninacallo. ${ }^{27}$ Si bien en este caso los padres no son parte del problema, el escrito describe una vasta gama de iniquidades y atropellos llevados a cabo con absoluta impunidad y, como los interesados señalan,

\footnotetext{
${ }^{23}$ ANB, 1762, 65-76 v.

${ }^{24}$ ANB, 1762, 77-83 v.

${ }^{25}$ La afirmación deja entrever cierta rivalidad entre los “incas” de Santa Cruz y el resto de las parcialidades originarias, que sería de interés explorar.

${ }^{26}$ Colquehaques (hombres de plata) eran llamados los indios ricos que pagaban al cacique para no mitar, a diferencia de los marahaques (indios del año) que eran alquilados por los caciques a los mineros como mano de obra por un valor similar (150 pesos) (Wachtel, 2001: 445).
}

${ }^{27}$ ANB, 1698, AN nro. 23. 
estas iniquidades ocurrían a la vista y ante la total inacción de los curas. Sin duda este proceder motivó la contemporánea censura del visitador Altamirano que mencionamos arriba relativa al abandono por parte de los padres de la protección y defensa de los indígenas. En todo caso, el documento muestra una realidad muy alejada de la idílica visión de la "colmena" a la que acudían a refugiarse los castigados indios de la provincia.

Como se desprende de las declaraciones y datos expuestos, hay evidencias de que, por largos períodos, en Juli no todo funcionaba bien o al menos, tan bien como se ha pretendido o, dicho de otro modo, de que la doctrina de los jesuitas no estaba exenta de los males que sufrían los indios en las reducciones. Las quejas de los indígenas apuntan a varios de los "lugares comunes" del abuso: (1) el mal trato físico por parte de los padres (en sus propias celdas), que echa por tierra la afirmación de que el castigo era impuesto por autoridades civiles; (2) el uso de los indios para el tráfico de mercancías, (3) la apropiación de parte de sus tierras, en este caso con el fin de dar lugar a los forasteros, (4) el exceso en el cobro de aranceles, (5) el abandono de los indios a la codicia de los caciques y a la corrupción de los funcionarios. Como vimos, estos perjuicios no se desprenden solamente de las declaraciones de los indios, sino que cuentan con avales externos: en primer lugar la crítica de algunos de los visitadores de la propia orden pero también la justicia, ya que, si la recomendación del gobernador de elevar la denuncia de los indios a los tribunales superiores no conlleva la declaración de culpabilidad de los imputados, implica necesariamente la seriedad del caso, al mismo tiempo que la dilución de los resultados prácticos en los inciertos vericuetos de la Audiencia.

El reclamo contra las ventajas otorgadas a los yanaconas corre a mi ver por otro andarivel, que no es el simple aprovechamiento económico de la situación de poder sino la construcción de un sistema productivo semiesclavista basado en las ventajas que otorgaba a los forasteros su condición de tales. El planteo parece haber intercambiado trabajo y tierra (particularmente la estancia de Suvicani pero quizás otras tierras de indios, como se desprende de su denuncia) por protección contra la mita y el tributo. Es preciso recordar que los jesuitas emplearon en gran escala el trabajo esclavo -situación equiparable a la de los yanaconas andinos- en sus estancias, por ejemplo en Córdoba. Cuando la ventaja de la excepción desapareció, a fines del siglo XVII y hacia 1760, el sistema pareció venirse abajo y el mismo rector de Juli, el padre Albizuri, afirma que al derogarse la exención de la mita para los yanaconas dos terceras partes de los forasteros habían partido masivamente con sus familias hacia otros rumbos. Esta perspectiva permite considerar con cierta distancia la magnanimidad de los juicios vertidos sobre Juli o a poner al menos parcialmente en duda el argumento demográfico, ya que la afluencia de foráneos no parece deberse tanto a la atracción del "pueblo santo" como al hallazgo de un espacio estable donde escapar de la mita a Potosí. Evidentemente nada de esto asoma en la valoración de la historiografía jesuítica de las razones de afluencia de indios ajenos a la doctrina, invariablemente presentada como resultado del ejercicio caritativo y de los alcances pastorales del adoctrinamiento. Siendo cierto que Juli ofrecía mejores condiciones que los pueblos de origen (al menos para los oriundos radicados en ellos y sujetos a las cargas prescriptas), la pintura ofrecida de las causas del tránsito dista de la realidad y oculta los intereses en que se fundaba: la captación y el empleo de 
forasteros parece denotar menos el generoso ejercicio de la caridad cristiana que el montaje y usufructo de un modo de producción encubierto bajo la forma del albergue. Pese a esto, parece evidente que si el régimen de yanaconas atraía forasteros era porque era preferible a otras alternativas, pero este hecho no debe confundir las razones que se cruzan para hacer posible que intereses tan diversos como los de los "vagos y forasteros" y los de los padres confluyan en un proyecto común. La dependencia del trabajo de los yanas lo admiten los religiosos cuando señalan la necesidad de reemplazarlos por otra gente de servicio. Es pues difícil abrir aquí un juicio ligado a intenciones morales o programas pastorales porque el cruce con intereses prácticos resta validez al argumento. La reiteración y uniformidad de determinadas valoraciones no debe llevar a la aceptación acrítica de esos juicios.

Para concluir: es evidente que la documentación expuesta es puntual y acaso también parcial. No pretendo, por lo tanto, dar por concluido el tema. Sin embargo el cruce de documentos y aún las contemporáneas instancias críticas de la misma orden muestran de modo indudable aspectos que no aparecen en las descripciones clásicas de Juli. La mayoría de los conflictos presentados -a excepción del caso de los forasteros-, como su resolución, se encuadran perfectamente en los tipos y procedimientos operantes en las doctrinas de indios ordinarias. En períodos que se extienden por décadas, la presencia jesuítica parece responsable, por acción u omisión, de la crítica situación y es necesario apuntar que, contra las opiniones corrientes, estos conflictos no se deben a causas externas sino al modo de operar de los propios padres. Por otro lado, el control de Juli por los jesuitas se extiende a lo largo de un lapso de tiempo (191 años) demasiado largo para permitir una valoración uniforme. No hace falta aclarar que tanto los ejecutores como el contexto se modificaron necesariamente, y si los primeros padres impulsaron fervientemente la obra pastoral y las empresas que dieron fama a la doctrina, ya en 1581 la presencia en Juli de Miguel Fuentes apoyado por el provincial Bartolomé Piñas, condenado por la Inquisición por depravación moral y reticente a aprender la lengua, contrario al ejercicio de la caridad entre los indígenas y proclive a la exacción de sus fondos, ${ }^{28}$ muestra claramente que la idealidad del programa no era igual a la práctica. Pero también las relaciones con las instituciones reales y los funcionarios, la normativa y los recursos sufrieron indudablemente cambios a lo largo de esos casi dos siglos, los que necesariamente deben haber modificado las intenciones originales y las condiciones en que se desenvolvían.

Creo que las consideraciones precedentes obligan a revisar seriamente las bases sobre las que se apoya la visión idílica del Juli jesuítico y a mi juicio difícilmente podría ser de otro modo. En primer lugar porque, como señalé al principio, Juli estaba inserta en el esquema de organización institucional general diseñado por Toledo para los pueblos de indios, con todo lo que esto conllevaba en aspectos tan importantes como las tasas, la mita y la posesión de las tierras. Pero no

${ }^{28}$ Meiklejohn, 1988: 207 y 210-211.

96 Ricardo González. El Juli jesuítico.¿Modelo misional o Proyección historiográfica.... 85-100 
sólo por eso. La experiencia de Juli -como casi todas- formaba parte de un conjunto de usos -fueran de jure o de facto- que moldeaba las relaciones interétnicas según patrones consuetudinarios y redes de poder y connivencia establecidas a través de los años que, más allá de las voluntades particulares -y creo que la Compañía tuvo como institución desde el comienzo el propósito de eludir estos caminos--, ${ }^{29}$ terminaban asfixiando las buenas intenciones en una trama ineludible. La alianza entre caciques, funcionarios, jueces y curas -cambiante en su composición según lugar y momento pero siempre activa en alguna de sus variantes- era un corsé difícil de salvar para las comunidades de indios llanos y numerosos documentos de la provincia de Chucuito o de otras dan cuenta de esta situación de impotencia que obligaba a los indios "a dejar nuestras propias mujeres y familia ... desamparar nuestras tierras y salir huidos sin una renta a perecer en esos montes y selvas privados del pasto espiritual", ${ }^{30}$ como lo expresan con tintes dramáticos los indígenas de Lípez. El estado de corrupción en que se desenvolvían las relaciones entre españoles, criollos e indígenas en el mundo colonial contaminaba todas las formas de la vida social, hecho que desalentaba profundamente a muchos de los religiosos al llegar a América con la ilusión de colaborar en un verdadero programa pastoral y que había hecho dudar al mismo Acosta de la participación de la Compañía en el proyecto reduccional de Toledo por temor de exponer a la tentación del lucro a los párrocos de indios. ${ }^{31}$ Es cierto que los jesuitas llamaron la atención repetidas veces sobre la presencia de españoles, mulatos y criollos en la reducción, intentando limitar su acción nociva, pero también lo es que su propia práctica no parece haber estado libre de la influencia "del estado de cosas" que los modos establecidos imponían o promovían. En relación con el daño que la mita y el tributo imponían -hecho del que obviamente la orden no era responsable ni podía escapar- todo parece indicar que los jesuitas colaboraron a paliar la situación, bien de modo directo, asistiendo a los que partían, bien de modo indirecto y como vimos interesado, amparando a los que huían.

El desencanto que muchas de estas cuestiones pueden haber causado impulsó indudablemente la búsqueda de una escena menos contaminada en las selvas del Guayrá y quizás la energía volcada en el nuevo emprendimiento también obró negativamente sobre la exigencia puesta en desarrollar la doctrina en el Titicaca. Echánove señala la dinámica que parece generarse en la preeminencia dada a las misiones de Paraguay en el siglo XVII y la complementaria pérdida de interés de la orden por el proyecto de Juli, sujeto a condiciones que no podían modificarse radicalmente, apatía que parece traslucirse igualmente en la carencia de noticias en la documentación interna, contrastando con la profusión precedente. ${ }^{32}$ En la época de la expulsión -en realidad bastante antes- las cuatro parroquias se habían reducido a una (San Pedro), los anexos eran cubiertos por sustitutos contratados y monseñor Gregorio de Campos observó en su visita que en la misa del domingo "muchos

${ }^{29}$ Las recomendaciones de los generales a los provinciales y rectores en el sentido de evitar las políticas de lucro corrientes y preservar el sentido misericordioso en la vida reduccional apuntan en ese sentido.

\footnotetext{
${ }^{30}$ ANB, Real Cédula nro. 2094, 1762.

${ }^{31}$ Meiklejohn, 1988: 227 (nota 28).

32 Echánove, 1955: 139 y 142.
}

97 Ricardo González. El Juli jesuítico.¿Modelo misional o Proyección historiográfica...: 85-100 
parroquianos se limitaban a mascullar las partes de la oración que no conocían bien”, ${ }^{33}$ lo que parece reflejar un resultado doctrinal modesto para casi dos siglos de labor misional.

Coda: El título de este trabajo polariza deliberadamente las posiciones desde las que este proceso puede considerarse. Seguramente una pintura verosímil se encuentra a medio camino entre el panegírico y la total falsedad de la visión establecida. He querido complejizar el panorama, convencido de que nuevos matices darán al cuadro mejor definición y considerando que, al decir de Max Bloch, la tarea del historiador no es juzgar (para bien ni para mal), sino explicar. Es evidente que la relativización de las virtudes del "modelo Juli" conlleva la de su papel como experiencia base del programa paraguayo. Esta consideración, que desde Vargas Ugarte se reitera, está apoyada en la perspectiva de algunos miembros de la orden influyentes en el proceso, particularmente el padre Diego de Torres Bollo, artífice de la perdurabilidad de Juli y fundador de las misiones del Guayrá, quien pensaba en la doctrina peruana como "una plaza de armas" donde entrenar misioneros para otros destinos. $^{34}$ Sin embargo, esta visión militante de la evangelización, propia de los primeros tiempos en el Titicaca, no parece guardar continuidad a lo largo del opaco siglo XVII. Hay a mi ver un vínculo más complejo entre ambas experiencias que el que se ha aceptado.

En primer lugar es preciso considerar que el programa para Juli constituye la primera aproximación sostenida al problema de las doctrinas o misiones en territorios indígenas por parte de la orden en el Virreinato de Perú. Esa página en blanco la llenó en gran parte el provincial José de Acosta, un intelectual que piensa en términos etnológicos y didácticos y define varias de las líneas centrales de la acción: la idea de reducción, la cuestión planteada pero no resuelta de la lengua, el tratamiento de la ambigüedad idolátrica y la necesidad de crear ciertas rutinas edificantes, entre otras.

Estos temas habían sido tratados desde los tiempos de los franciscanos en México y aún antes, pero Acosta los enfoca con un criterio global, sistemático y empírico. Era además, como provincial, quien conducía la acción, lo que le daba poder de ejecución a sus planteos teóricos y contó en este sentido con la gestión, a todas luces notable, de Diego de Torres Bollo, sostén de la misión de Juli y primer provincial en las de Paraguay. Este es un plano. En él podríamos decir que se marcan ejes centrales de la actividad reduccional que operarán primero en Juli y luego en el Guayrá. Un segundo plano es el de la práctica, que como vimos, no siguió siempre los principios. Aquí, el vínculo de Paraguay con Juli -y Echánove lo sugiere- es el de una contrastación negativa: Juli no fue tanto un modelo de lo que se debía hacer, como de lo que había que evitar. Es cierto que muchos de los conflictos presentados ocurren en fecha posterior al establecimiento en el Guayrá, pero también que estas modalidades operaron tempranamente y que indudablemente generaban problemas,

\footnotetext{
${ }^{33}$ Meiklejohn, 1988: 218-219.

${ }^{34}$ Echánove, 1955: 139.
}

98 Ricardo González. El Juli jesuítico.¿Modelo misional o Proyección historiográfica.... 85-100 
como lo prueba la permanente necesidad de asistencia de la orden al entero de la mita. La solución a estas dificultades, que en el programa misional jesuítico posterior parece hacerse presente en aspectos tales como la necesidad de autonomía económica, la independencia del tributo y de la mita y la organización del trabajo indígena, abona la idea de una reflexión profunda acerca de los problemas que habían hecho fracasar las experiencias misionales anteriores, desde Santo Domingo y México al Collao y la consecuente búsqueda de soluciones. En cierta forma el desarrollo del urbanismo jesuítico parece seguir un camino paralelo, perfeccionando paulatinamente los modelos precedentes hasta su forma ideal. Pero la evolución se daba en una sola dirección y así la imagen de la reducción peruana que proyecta la documentación expuesta recuerda poco al orden misional posterior y sólo permite establecer un lazo analógico entre ambas experiencias en lo tocante a algunos aspectos e intenciones vinculados a la formulación inicial del proyecto. Contrariamente, los conflictos parecen indicar que las interpretaciones tardías del proceso histórico collavino deben más a la imagen del Paraguay misionero proyectado sobre la visión historiográfica de Juli, que la organización del Guayrá a la experiencia andina precedente.

\section{Referencias}

\section{Archivos}

ANB (Archivo Nacional de Bolivia, Sucre).

\section{Bibliografía}

Acosta, José de, (1954) [1588], De procuranda indorum salute, Madrid.

Vargas Ugarte SJ, Rubén (1941), Los jesuitas del Perú, Lima.

Ricard, Robert, (2005) [1933], La conquista espiritual de México, FCE, México.

Egaña SJ, Antonio de y Fernández SJ, Enrique (1954-1986). Monumenta Peruana (8 volúmenes) que integran la "Monumenta Historica Societatis Jesu”, Roma.

Echánove, Alfonso (1955), “Origen y evolución de la idea jesuítica de "reducciones” en las misiones del Virreinato del Perú”, Missionalia hispanica, nro. 12.

Gutiérrez, Ramón, (1986) [1978], Arquitectura del altiplano peruano. Buenos Aires: Libros de Hispanoamérica.

Meiklejohn, Norman (1988), La iglesia y los lupaqas durante la colonia, Cusco: Centro de Estudios Rurales Andinos "Bartolomé de las Casas"- Instituto de Estudios Aymaras. 
Page, Carlos (2012), Las otras reducciones jesuíticas. Emplazamiento territorial, desarrollo urbano y arquitectónico. Siglos XVII y XVIII, Saarbrücken: Editorial Académica Española.

Wachtel, Nathan (2001), El regreso de los antepasados. Los indios urus en Bolivia, del siglo $X X$ al $X V I$, FCE, México. 